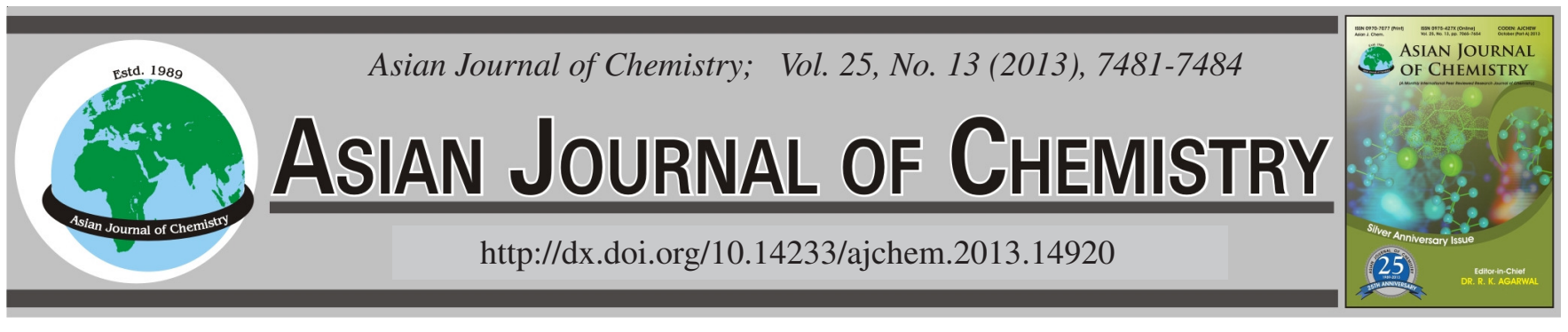

\title{
Determination of Montelukast Sodium in Raw Material and Solid Dosage Form Using Reverse Phase HPLC
}

\author{
Syed Saeed-Ul-Hassan ${ }^{1}$, Ahsan-Ul-Haq Ather ${ }^{1}$, Muhammad Tayyab Ansari ${ }^{2}$, Imran Tariq ${ }^{1, *}$ and Sabiha Karim $^{1}$
}

${ }^{1}$ University College of Pharmacy, University of the Punjab, Lahore-54000, Pakistan

${ }^{2}$ Department of Pharmacy, Bahauddin Zakariya University, Multan, Pakistan

*Corresponding author: Tel: +92 3224218583; E-mail: imran_1982@hotmail.com

(Received: 5 December 2012;

Accepted: 1 July 2013)

AJC-13733

\begin{abstract}
The purpose of the present study was to develop a new simple, accurate, precise and economic reverse phase HPLC method for the determination of montelukast sodium in bulk and pharmaceutical tablet dosage form. The separation of analyte was carried on lichorosovol octylsilyl $(5 \mu \mathrm{m} 250 \mathrm{~mm} \times 4.6 \mathrm{~mm}) \mathrm{C}_{8}$ column and the mobile phase was fixed to acetonitrile and sodium acetate buffer (adjusted to $\mathrm{pH}$ 4 with acetic acid), in the proportion of $80: 20 \mathrm{v} / \mathrm{v}$, UV detection was carried out at $350 \mathrm{~nm}$ with a flow rate of $1 \mathrm{~mL} / \mathrm{min}$. The developed method showed that Beer's law was obeyed in range of $0.00008-0.2 \mathrm{mg} / \mathrm{mL}$ having correlation coefficient $\left(\mathrm{R}^{2}\right)$ of 0.999 . The per cent recovery was found from 100-103.28\% which indicate that the method is precise and reproducible. LOD and LOQ of drug were 0.00008 and $0.004 \mathrm{mg} / \mathrm{mL}$, respectively. Precision, specificity, robustness studies showed good repeatability of the applied method. Percentage relative standard deviation values were found less than $2 \%$ for proposed method. It was concluded that proposed method was versatile, low cost, accurate, selective, precise and rapid for the analysis of montelukast sodium.
\end{abstract}

Key Words: Montelukast sodium, RP-HPLC, Validation.

\section{INTRODUCTION}

Montelukast sodium, [(R)-(E)]-1-[[[1-[3-[2-[7-chloro-2quinolinyl)ethenyl]phenyl]-3-[2-(1-hydroxy-1-methylethyl) phenyl]propyl] thio]methyl] cyclopropane acetic acid, monosodium salt $\left(\mathrm{C}_{35} \mathrm{H}_{35} \mathrm{O}_{3} \mathrm{SClNa}\right)$ (Fig. 1), a synthetic leukotrienereceptor antagonist, is an antiasthmatic agent ${ }^{1-8}$. Montelukast is a cysteinyl leukotriene analog that was developed based on a quinoline- containing compound that was modified with leukotriene structural elements. Structural modification resulted in improved potency, oral bioavailability, clinical efficacy and/ or safety profile relative to early leukotriene antagonists (e.g. MK-571, verlukast $)^{9}$ but these agents are les effective than inhaled corticosteroids ${ }^{10}$ and generally are not preferred as initial therapy ${ }^{10,11}$. It has been reported that no dose adjustments are necessary when montelukast sodium is used for patients with renal and mild to moderate hepatic dysfunction and very much safe in children as well ${ }^{5,12,13}$.

Literature survey reveals the availability of liquid chromatography with fluorescence detector ${ }^{14}$, stereoselective high performance liquid chromatography (HPLC) ${ }^{15}$, column switching HPLC with fluorescence detector ${ }^{16}$, semi-automated 96-well protein precipitation ${ }^{17}$, HPLC with derivative spectroscopy ${ }^{18}$, pressurized liquid extraction followed by HPLC ${ }^{19}$ and LC-MS methods ${ }^{20-22}$ for the estimation of montelukast sodium. The<smiles>CC(C)(O)c1ccccc1CCC(SCC1(CC(N)=O)CC1)c1cccc(C=Cc2ccc3ccc(Cl)cc3n2)c1</smiles>

Fig. 1. Chemical structure of montelukast sodium

aim behind the present study was to device a new a rapid, efficient, simple and validated reverse phase high performance liquid chromatography method for the separation and quantification of process of montelukast sodium. The accuracy, precision, limit of detection (LOD), limit of quantification (LOQ), specificity and robustness of the method were determined in accordance with ICH guidelines.

\section{EXPERIMENTAL}

Acetonitrile HPLC Grade, Water for HPLC, sodium acetate AR grade, Acetic Acid HPLC grade and triethanolamine AR grade were procured from Merck.

A Shimadzu 10 A HPLC isocratic system was employed for RP-HPLC method development. Lichorosovol Octylsilyl $5 \mu \mathrm{m} 250 \mathrm{~mm} \times 4.6 \mathrm{~mm} \mathrm{C}_{8}$ was used for drug separation. A sample volume of $20 \mu \mathrm{L}$ was used throughout the analysis. 
The column temperature was maintained at $40^{\circ} \mathrm{C}$. The mobile phase was optimized with acetonitrile and sodium acetate buffer (adjusted to $\mathrm{pH} 4$ with acetic acid), in the proportion of $80: 20 \mathrm{v} / \mathrm{v}$, UV detection was carried out at $350 \mathrm{~nm}$ with a flow rate of $1 \mathrm{~mL} / \mathrm{min}$. Flush the column with methanol for at least $0.5 \mathrm{~h}$ and then stabilize the column at the initial mobile phase composition. Inject the solution and record the chromatogram for $15 \mathrm{~min}$. The data was acquired and analyzed by LC solution software.

Preparation of mobile phase: Accurately weigh $3.4 \mathrm{~g}$ of sodium acetate and dissolve in $750 \mathrm{~mL}$ water and make up the volume up to $1 \mathrm{~L}$. Add $0.5 \mathrm{~mL}$ triethanolamine and adjust the $\mathrm{pH}$ to 4 with acetic acid. Take $200 \mathrm{~mL}$ of sodium acetate solution and add $800 \mathrm{~mL}$ of acetonitrile in it to get mobile phase with following ratio.

$\begin{array}{rll}\text { Acetonitrile } & : & \text { Sodium acetate solution } \\ 80 & : & 20\end{array}$

Filter the whole mobile phase through whatman filter paper of $(0.45 \mu)$ using vacuum pump.

Standard solution preparation: Accurately weighed and transferred $c a .8 .4 \mathrm{mg}$ of montelukast sodium in $100 \mathrm{~mL}$ amber coloured volumetric flask. Add ca. $70 \mathrm{~mL}$ of diluent (mobile phase), sonicate to dissolve and make up the volume with diluent to obtain a concentration of about $0.08 \mathrm{mg} / \mathrm{mL}$. Filter the solution through Whatman filter paper No. 42. Further dilutions were made to obtain the concentration in the range of $0.00008-0.2 \mathrm{mg} / \mathrm{mL}$ of montelukast sodium.

Preparation of sample/assay solution: Weigh 20 tablets containing montelukast sodium, grind them in in pestle and mortor. Accurately weigh the powder (crushed) containing $8 \mathrm{mg}$ of montelukast sodium and transfer it in $100 \mathrm{~mL}$ amber coloured volumetric flask. Add ca. $70 \mathrm{~mL}$ of diluent (mobile phase), sonicate to dissolve and make up the volume with diluent. Filter the solution through Whatman filter paper No. 42. The system suitability was checked by injecting $20 \mu \mathrm{L}$ of standard solution and found the results within the range. The relative standard deviation on six replicate injections was not more than $2.0 \%$. Twenty microlitres of standard and sample solutions were separately injected on HPLC system. From the peak area of montelukast the amount of drugs in the sample were computed by using the following formula:

$$
\begin{aligned}
\text { Assay } & =\frac{\text { Av. area of sample }}{\text { Av. area of standard }} \times \frac{\mathrm{Wt} \text {. of standard }}{\mathrm{Wt} \text {. of sample }} \\
& \times \text { Purity of standard } \times \text { wt. of tablet (as is basis) }
\end{aligned}
$$

Validation: The developed method was validated in terms of specificity, linearity, accuracy, limit of detection, limit of quantification, intra-day and inter-day precision and robustness for the assay of montelukast sodium as per ICH guidelines.

\section{RESULTS AND DISCUSSION}

A typical chromatogram of standard solution $(0.08 \mathrm{mg} /$ $\mathrm{mL}$ ) of montelukast sodium is shown in Fig. 2. The peak areas obtained after the injections of standard solution of montelukast sodium is given in Table- 1 .

Linearity and range: Linearity was studied by preparing standard solutions of montelukast at different concentration levels in the range of $0.00008-0.2 \mathrm{mg} / \mathrm{mL}(0.1-250 \%)$ of the

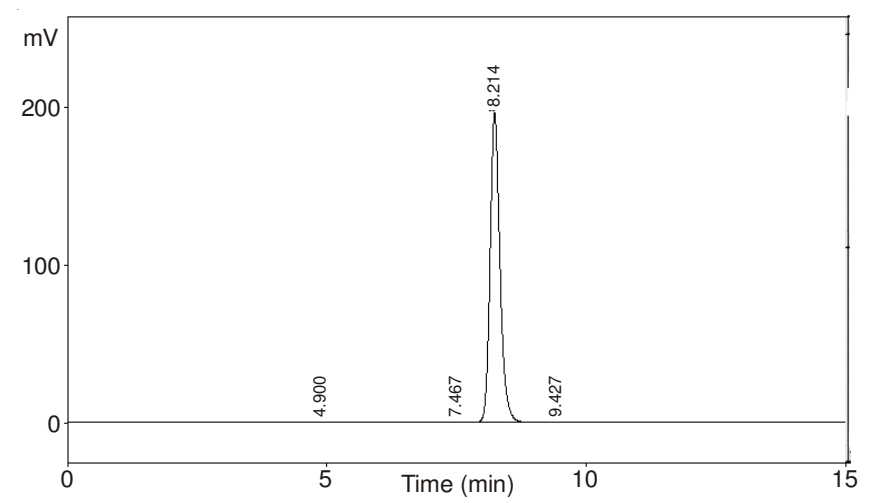

Fig. 2. A typical chromatogram of montelukast sodium standard $(0.08 \mathrm{mg} /$ $\mathrm{mL}$ )

\begin{tabular}{ccc}
\multicolumn{3}{c}{ TABLE-1 } \\
\multicolumn{3}{c}{ PEAK AREAS OBTAINED AFTER THE } \\
INJECTIONS OF STANDARD SOLUTION \\
\hline S. No. & Peak Area & Contents $(\%)$ \\
\hline 1 & 2603720 & 99.75 \\
2 & 2608064 & 99.91 \\
3 & 2614413 & 100.16 \\
4 & 2610387 & 100.00 \\
5 & 2612700 & 100.09 \\
6 & 2612891 & 100.10 \\
Mean & 2610363 & 100.00 \\
RSD $(\%)$ & & \\
\hline
\end{tabular}

theoretical concentration in the sample preparation $0.08 \mathrm{mg} / \mathrm{mL}$ (100\%) as listed in Table-2. The linearity of detector response was established by plotting a graph between concentration and peak areas of montelukast standard drug (Fig. 3). The detector response was found to be linear for these dilutions and correlation coefficient $\left(\mathrm{R}^{2}\right)$ value was equal to 0.999 . The Y-equation for montelukast concentrations was $\mathrm{y}=30000000 \mathrm{x}+16850$ (Table-3).

\begin{tabular}{ccc}
\multicolumn{4}{c}{ TABLE-2 } \\
\multicolumn{3}{c}{ BEER'S LAW RANGE FOR LINEARITY } \\
DERTERMINATION OF MONTELUKAST SODIUM \\
\hline S. No. & Conc.(mg/mL) & Peak areas \\
\hline 1 & 0.00008 & 2931 \\
2 & 0.0008 & 26431 \\
3 & 0.004 & 135509 \\
4 & 0.008 & 270611 \\
5 & 0.04 & 1320947 \\
6 & 0.08 & 2617296 \\
7 & 0.2 & 6395716 \\
\hline
\end{tabular}

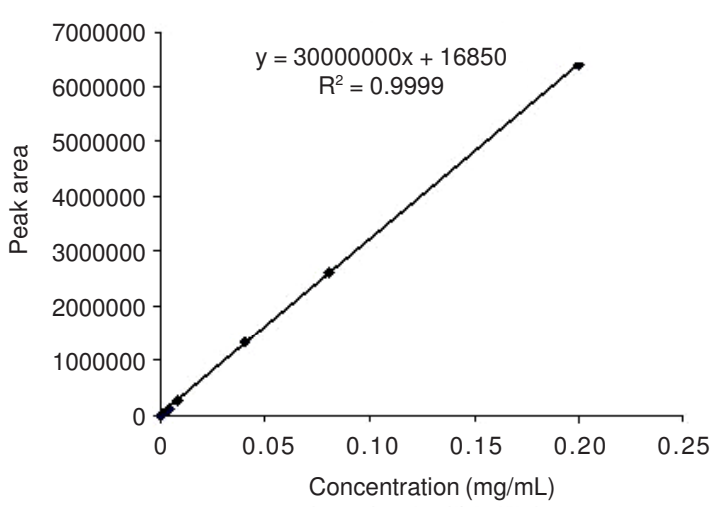

Fig. 3. Standard curve of montelukast sodium 
TABLE-3

LINEARITY PARAMETERS OF MONTELUKAST SODIUM

\begin{tabular}{lc}
\hline \multicolumn{1}{c}{ Parameters } & Montelukast sodium \\
\hline Beer's law range $\left(\mathrm{mg} \mathrm{mL}^{-1}\right)$ & $0.00008-0.2$ \\
Slope & 30000000 \\
Intercept & 16850 \\
Correlation co-efficient & 0.9999 \\
\hline
\end{tabular}

Quantitation limit/detection limit: The quantitation limit is a characteristic of quantitative assay for low levels of compounds in sample matrix, such as impurities in bulk drug substances and degradation products in finished pharmaceuticals. The detection limit is the lowest amount of the analyte/ sample that can be detected, but not necessarily quantitated ${ }^{23-25}$. Linearity curve shows that concentration up to $0.004 \mathrm{mg} / \mathrm{mL}$, curve is linear, so we can quantify montelukast sodium at the concentration beyond the concentration we can detect the montelukast sodium at $0.00008 \mathrm{mg} / \mathrm{mL}$ (Table-4).

\begin{tabular}{ccc}
\multicolumn{3}{c}{ TABLE-4 } \\
\multicolumn{3}{c}{ LIMIT OF DETECTION AND LIMIT } \\
OF QUATITATION PARAMETERS \\
\hline Parameter & Conc. $(\mathrm{mg} / \mathrm{mL})$ & Peak areas \\
\hline LOD & 0.00008 & 2931 \\
LOQ & 0.004 & 135509 \\
\hline
\end{tabular}

Precision (repeatability): The precision of an analytical procedure is the degree of agreement among individual test results when the procedure is applied repeatedly to multiple sampling of homogeneous sample. Precision may be a measure of either the degree of reproducibility or of the repeatability of the analytical procedure under normal operating conditions. Reproducibility refers to use of analytical procedure in different laboratories, as in a collaborative study. Intermediate precision (may also known as ruggedness) expresses with in laboratory variation, as on different days or with different analysts or equipment with in the same laboratory. Repeatability refers to use the analytical procedure with in the laboratory over a short period of time using the same analyte with in the same equipment ${ }^{23-25}$. Six injection of the sample solution (concentration $0.08 \mathrm{mg} / \mathrm{mL}$ ) showed results in the range of 98.45-100.84\%. Percentage relative standard deviation (RSD \%) values were found less than $2 \%$ that illustrates the good precision of the proposed method (Table-5).

\begin{tabular}{ccc}
\multicolumn{4}{c}{ TABLE-5 } \\
PRECISION STUDY OF MONTELUKAST SODIUM \\
\hline S. No. & Peak Area & Content $(\%)$ \\
\hline 1 & 2603720 & 99.75 \\
2 & 2608064 & 99.91 \\
3 & 2614413 & 100.16 \\
4 & 2610387 & 100.00 \\
5 & 2612700 & 100.09 \\
6 & 2612891 & 100.10 \\
Mean & 2610363 & 100.00 \\
RSD (\%) & & 0.001 \\
\hline
\end{tabular}

Accuracy (recovery): Weight of montelukat sodium (100 $\% 0.08 \mathrm{mg} / \mathrm{mL}$ ) were added to the amount of placebo mixture equivalent to the amount of placebo present in sample solution preparation. Three solutions were prepared, spiked at 80, 100 and $120 \%$ of the theoretical sample solution concentrations. These mixtures were subjected to the HPLC procedure and the amount of montelukast sodium recovered from each mixture was calculated. The \% RSD was found less than $2 \%$ (Table-6).

Stability of the solution: Injections of standard solution stored at room temperature over the period of $6 \mathrm{~h}$ showed no significant difference in the peak area of montelukast sodium. Results are shown in the Table-7.

Specificity: Specificity is the ability to assess the unequivocally the analyte in the presence of components that may be expected to be present, such as impurities, degradation products and matrix components. Prepare the solution of excepients with out montelukast sodium and observed the graph. And run this solution through HPLC procedure. No interference was observed in the chromatogram at the RT of the montelukast sodium (Fig. 4).

Robustness/ruggedness: Robustness of an analytical procedure is a measure of its capacity to remain unaffected by small but deliberate variations in procedural parameters listed in the procedure. Ruggedness measure the concentration of analyte different operators, different equipment or source of materials. Same method was performed by different people but no change in the peak was found. These results confirm the degree or reproducibility and reliability of the method.

\section{Conclusion}

Finally, it is concluded that this method is entirely reliable and suitable for the determination of montelukast sodium

\begin{tabular}{|c|c|c|c|c|c|c|}
\hline \multicolumn{7}{|c|}{$\begin{array}{c}\text { TABLE-6 } \\
\text { ACCURACY/RECOVERY DATA FOR MONTELUKAST SODIUM }\end{array}$} \\
\hline S. No. & Conc. (mg/mL) & Solution $(\%)$ & Peak area & Average & Recovery (\%) & Content (\%) \\
\hline 1 & \multirow{3}{*}{0.064} & \multirow{3}{*}{75} & 2017725 & \multirow{3}{*}{2021988} & \multirow{3}{*}{77.46} & \multirow{3}{*}{103.28} \\
\hline 2 & & & 2023013 & & & \\
\hline 3 & & & 2025226 & & & \\
\hline 4 & \multirow{6}{*}{0.080} & \multirow{6}{*}{100} & 2603720 & \multirow{6}{*}{2610363} & \multirow{6}{*}{100.00} & \multirow{6}{*}{100.00} \\
\hline 5 & & & 2608064 & & & \\
\hline 6 & & & 2614413 & & & \\
\hline 7 & & & 2610387 & & & \\
\hline 8 & & & 2612700 & & & \\
\hline 9 & & & 2612891 & & & \\
\hline 10 & \multirow{3}{*}{0.096} & \multirow{3}{*}{120} & 3326555 & \multirow{3}{*}{3333028} & \multirow{3}{*}{127.70} & \multirow{3}{*}{102.16} \\
\hline 21 & & & 3331740 & & & \\
\hline 22 & & & 3340789 & & & \\
\hline Mean & & & & 101.81 & & \\
\hline $\operatorname{RSD}(\%)$ & & & & 0.016 & & \\
\hline
\end{tabular}


TABLE-7

STABILITY DATA FOR MONTELUKAST SODIUM

\begin{tabular}{cccc}
\hline S. No. & Time $(\mathrm{h})$ & Peak area & Contents $(\%)$ \\
\hline 1 & 0 & 2603720 & 100.00 \\
2 & 1 & 2612700 & 100.34 \\
3 & 2 & 2617845 & 100.54 \\
4 & 3 & 2629045 & 100.97 \\
5 & 4 & 2633326 & 101.14 \\
6 & 5 & 2639726 & 101.38 \\
7 & 6 & 2647610 & 101.69 \\
Mean & & 2626282 & 100.87 \\
RSD (\%) & & \multicolumn{2}{c}{0.55} \\
\hline
\end{tabular}

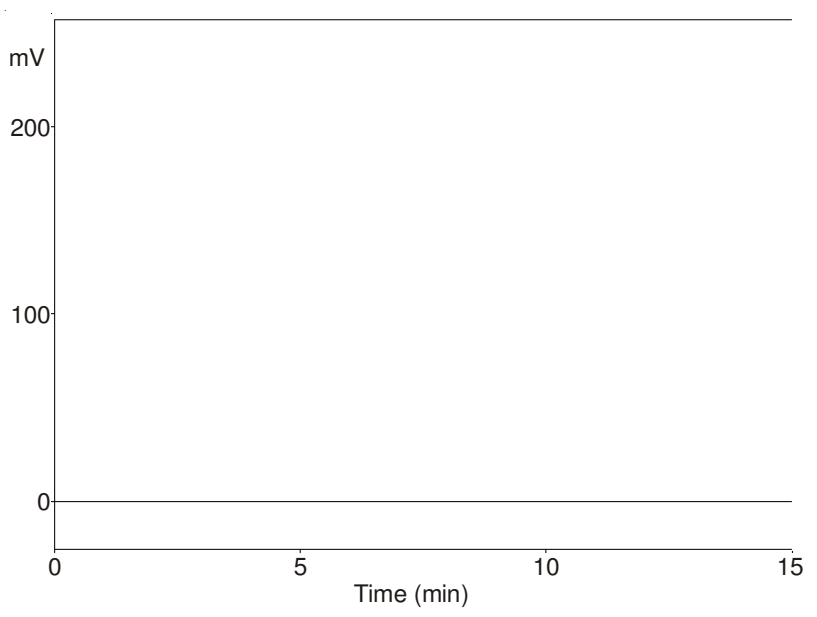

Fig. 4. Blank chromatogram with out Montelukast sodium

for both raw material and finished pharmaceutical products on both isocratic and gradient systems, as it has proved its accuracy with various pharmaceutical products and so this method can be used for the routine analysis of Montelukast sodium in quality control laboratories and can be proved a good tool for the dissolution testing profile for montelukast sodium tablet dosage form.

\section{REFERENCES}

1. J.M. Drazen, Pharmacotherapy, 17, 22S (1997).

2. R. Thibert, H. March, S.D. Clas and E.B. Vadas, Int. J. Pharm., 134, 59 (1996).
3. D.W.P. Hay, Chest, 111, 35 (1997).

4. Merk and Co, Whitehouse Station, New Jersy (2006).

5. G. Rechelefsky, J. Pediatr., 131, 348 (1997).

6. T.F. Reiss, C.A. Sorkness, W. Stricker, A. Botto, W.W. Busse, S. Kundu and J. Zhang, Thorax., 52, 45 (1997).

7. I. De Lepeleire, T.F. Reiss, F. Rochette, A. Botto, J. Zhang, S. Kundu and M. Decramer, Clin. Pharmacol. Ther., 61, 83 (1997).

8. B. Jarvis and A. Markham, Drugs, 59, 891 (2000).

9. L.J. Smith, Ann. Intern. Med., 130, 531 (1999).

10. National Institute of Health, Heart, Lungs, Blood Institute, Globle Initiative for Asthma Management and Prevention NHLBI/ WHO Workshop Report. Bestheda MD, National Institute of Health, NIH/NHLBI Publication No. 02-3659 (2005).

11. National Asthma Education and Prevention Program. Expert panel report: Guidelines for the Diagnosis and Management of Asthma-Update on Selected Topics 2002, Bethesda, Md: National Heart, Lung and Blood Institute, National Asthma Education and Prevention Program Coordinating Committee, Jun. Available from National Heart, Lung and Blood Institute Information Center, NIH Publication No. 02-5074 (2003).

12. R. Cuchacovich, M. Justiniano and L.R. Espinoza, Clin. Rheumatol., 26, 1769 (2007).

13. C. Boccagni, F. Tesser, D. Mittino, E. Terazzi, P. Naldi, S. Colombi, E. Zoppis and F. Monaco, Neurol. Sci., 25, 21 (2004).

14. R.D. Amin, H. Cheng and J.D. Rogers, J. Pharm. Biomed. Anal., 13, 155 (1995).

15. L. Liu, H. Cheng, J.J. Zhao and J.D. Rogers, J. Pharm. Biomed. Anal., 15, 631 (1997).

16. H. Ochiai, N. Uchiyama, T. Takano, K. Hara and T. Kamei, J. Chromatogr. B: Biomed. Appl., 713, 409 (1998).

17. C.J. Kitchen, A.Q. Wang, D.G. Musson, A.Y. Yang and A.L. Fisher, J. Pharm. Biomed. Anal., 31, 647 (2003).

18. T. Radhakrishna, A. Narasaraju, M. Ramakrishna and A. Satyanarayana, J. Pharm. Biomed. Anal., 31, 359 (2003).

19. T.H. Hoang, R. Farkas, C. Wells, M. Cliutock and M.D. Maso, J. Chromatogr. A., 968, 257 (2002).

20. P. Robert, L. Pauline, M. Wayne and K. Elizabeth, J. Chromatogr. B, 858, 282 (2007).

21. B. Satyanarayana, K.S. Kumari, P.P. Reddy, M.N. Naidu, J.M. Babu and A.K. Srivavtava, J. Pharm. Biomed. Anal., 48, 708 (2008).

22. M. Mahmoud, A. Omari, R.M. Zoubi, E.I. Hasan, T.Z. Khader and A.A. Badwan, J. Pharm. Biomed. Anal., 45, 465 (2007).

23. D.G. Watson, Pharmaceutical Analysis: A Text Book for Pharmacy Students and Pharmaceutical Chemist, 1, 1-11, 49-50, 75-110 (1999).

24. P.D. Sethi, HPLC: Quantitative Analysis of Pharmaceutical Formulations, CBS Publishers \& Distributors, New Delhi (2001).

25. Validation of Compendial and Non-Compendial Methods: USP, 680686 (2003). 